\title{
铱催化乙烯基叠氮和外消旋烯丙基碳酸酯的高对映选择性偶联反应
}

\author{
张辉刘文博*
}

(武汉大学化学与分子科学学院 武汉 430072)

\section{Highly Enantioselective Iridium-Catalyzed Coupling Reaction of Vinyl Azides and Racemic Allylic Carbonates}

\author{
Zhang, Hui Liu, Wenbo*
}

(College of Chemistry and Molecular Sciences, Wuhan University, Wuhan 430072)

金属铱催化的不对称烯丙基烷基化反应是一类构 建手性中心最重要的方法之一 ${ }^{[1]}$. 自从 1997 年铱催化的 烯丙基化被首次发现以来 ${ }^{[2-3]}$, 丙二酸酯、丙二腈等容易 形成稳定的碳负离子的亲核试剂参与此类不对称烯丙 基烷基化反应被陆续报道 ${ }^{[1]}$. 但是对于一些简单的羰基 化合物，由于会形成 “硬” 的不稳定的烯醇化物，反应 时不能与烯丙基亲电试剂较好地匹配, 是一类非常具有 挑战性的亲核试剂. 因此寻找这些 “硬” 亲核试剂的合 适的替代物是解决该问题的有效策略之一.

酰胺和腈是有机合成中重要的合成砌块, 在生物化

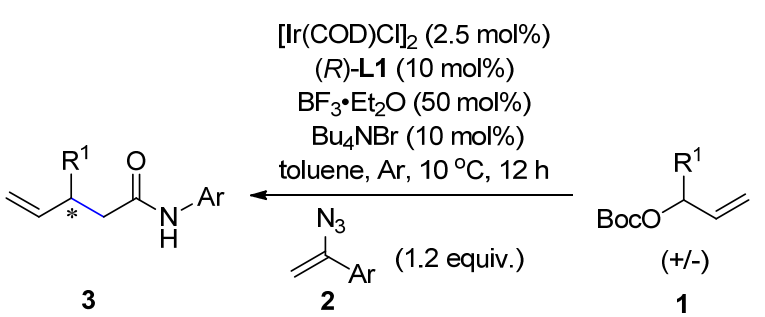

学和材料化学中应用广泛 ${ }^{[4]}$. 然而使用酰胺或者腈直接 作为亲核试剂的烯丙基烷基化反应具有很大的挑战性, 这主要是因为它们 $\alpha$ 碳负离子 “硬” 的亲核性会导致副 反应的发生 ${ }^{[5]}$. 近日, 四川师范大学化学与材料科学学 院曹鹏课题组以 $[\mathrm{Ir}(\mathrm{COD}) \mathrm{Cl}]_{2}$ 和 Carreira 配体 $\mathbf{L 1}$ 原位生 成的金属铱络合物作为催化剂，在路易斯酸协同催化 下，实现了烯基叠氮和外消旋的烯丙基碳酸酯的不对称 亲核取代反应 ${ }^{[6]}$ (Scheme 1). 在该方法中，通过选择烯 基叠氮的取代基，可以实现产物类型的精准调控：当使 用 $\alpha$-芳基烯基叠氮 2 时得到酰胺类产物; 当使用
$\left[\mathrm{Ir}(\mathrm{COD}) \mathrm{Cl}_{2}(2.5 \mathrm{~mol} \%)\right.$

(R)-L1 (10 $\mathrm{mol} \%)$

$\mathrm{ZnCl}_{2}$ or $\mathrm{ZnBr}_{2}$ (15 $\left.\mathrm{mol} \%\right)$

toluene, $\mathrm{Ar}, 25^{\circ} \mathrm{C}, 12 \mathrm{~h}$

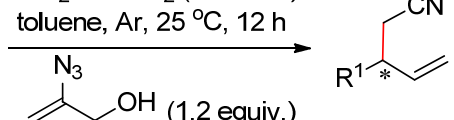

$<^{\mathrm{OH}}$ (1.2 equiv.)

4

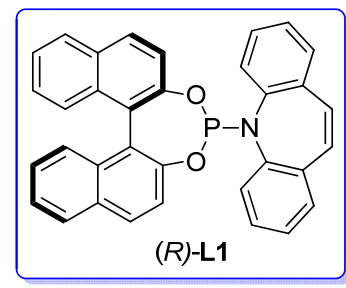<smiles>C=C[C@H](CC(=O)Nc1ccccc1)c1ccccc1</smiles>

$76 \%, 99 \%$ ee<smiles>C=CC(CC(=O)Nc1ccccc1)C1=C[N+](=S)c2ccccc21</smiles>

$42 \%, 94 \%$ ee<smiles>C=CC(CC(=O)Nc1ccccc1)c1ccc(C(F)(F)F)cc1</smiles>

$63 \%$, > 99\% ee<smiles>C=C[C@H](CC(=O)Nc1ccccc1)c1cccs1</smiles>

$53 \%, 98 \%$ ee<smiles>C=CC(CC(=O)Nc1ccccc1)c1ccc(Br)cc1</smiles>

$65 \%, 98 \%$ ee

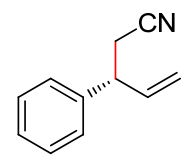

$95 \%,>99 \%$ ee<smiles>C=C[C@@H](CC#N)c1ccc(C(F)(F)F)cc1</smiles>

$60 \%, 99 \%$ ee<smiles>C=CC(CC#N)c1ccc(F)cc1</smiles>

$62 \%, 99 \%$ ee<smiles>C=C[C](CC#N)c1cccs1</smiles>

$41 \%$, > 99\% ee<smiles>C=C[C@H](CC#N)c1ccccc1Br</smiles>

$81 \%, 99 \%$ ee

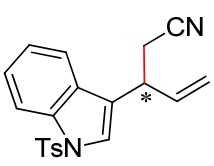

$65 \%$, > 99\% ee

图式 $1 \beta$-取代的 $\gamma, \delta$-不饱和酰胺和 $\gamma, \delta$-不饱和腈的代表性底物

Scheme 1 Representative substrates of $\beta$-substituted $\gamma, \delta$-unsaturated amides and $\gamma, \delta$-unsaturated nitriles

* Corresponding author. E-mail: wenboliu@whu.edu.cn. Published online December 6, 2020. 
$\alpha$-(2-羟基异丙基)烯基叠氮 4 时生成乙腈类衍生物. 该 方法条件温和, 具有优秀的对映选择性和区域选择性, 底物的兼容性良好(Scheme 1).

该方法的产物可以通过衍生化快速构建 2,3-二取代 四氢吡咯、七元环内酰胺、3,4-二氢喹诺林酮等重要的 合成砌块. 作者还使用烯丙醇作为底物, 在铱和三氯化 铟的作用下合成了化合物 7, 并通过氧基还原、双羟化 以及分子内亲核取代反应，以>99\% ee 合成了 GluN2B 抑制剂的重要中间体 8 (Scheme 2$)^{[7-8]}$.

在一系列机理实验和前人工作的基础上 ${ }^{[9]}$, 作者随 后提出了可能的催化循环机理(Scheme 3). 在路易斯酸 的作用下, $\operatorname{Ir}(\mathrm{I})$ 络合物与碳酸酯氧化加成得到烯丙基 Ir(III)中间体 I. 接着该中间体和烯基叠氮发生碳碳键偶 联得到亚氨基重氮离子中间体 II. 当烯基叠氮 $\alpha$ 位取代 基为芳基时, II 发生 1,2-苯基迁移得到高活性的腈离子 III, 随即发生醇解(水解)得到酰胺类产物; 当烯基叠氮 $\alpha$ 位取代基为 2 -羟基异丙基时, II 经过碎片化得到 $\beta$-取 代的戊-4-烯腈类产物.

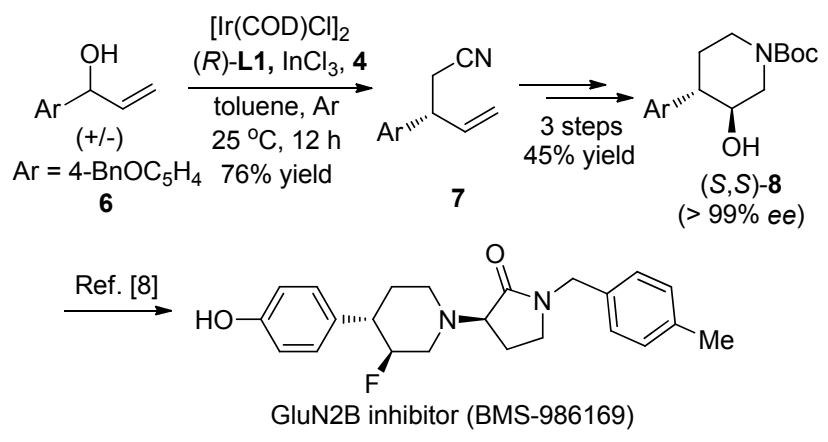

图式 2 BMS-986169 中间体的合成

Scheme 2 Synthesis of the intermediate of BMS-986169

综上所述，曹鹏等利用烯基叠氮作为酰胺烯醇和乙 腈碳负离子的替代物，实现了形式上的金属铱催化的酰 胺和乙腈的不对称烯丙基烷基化反应，丰富了不对称烯 丙基烷基化反应中亲核试剂的种类，并通过产物的衍生 化和对药物分子中间体的合成，阐述了该方法的应用潜 力.

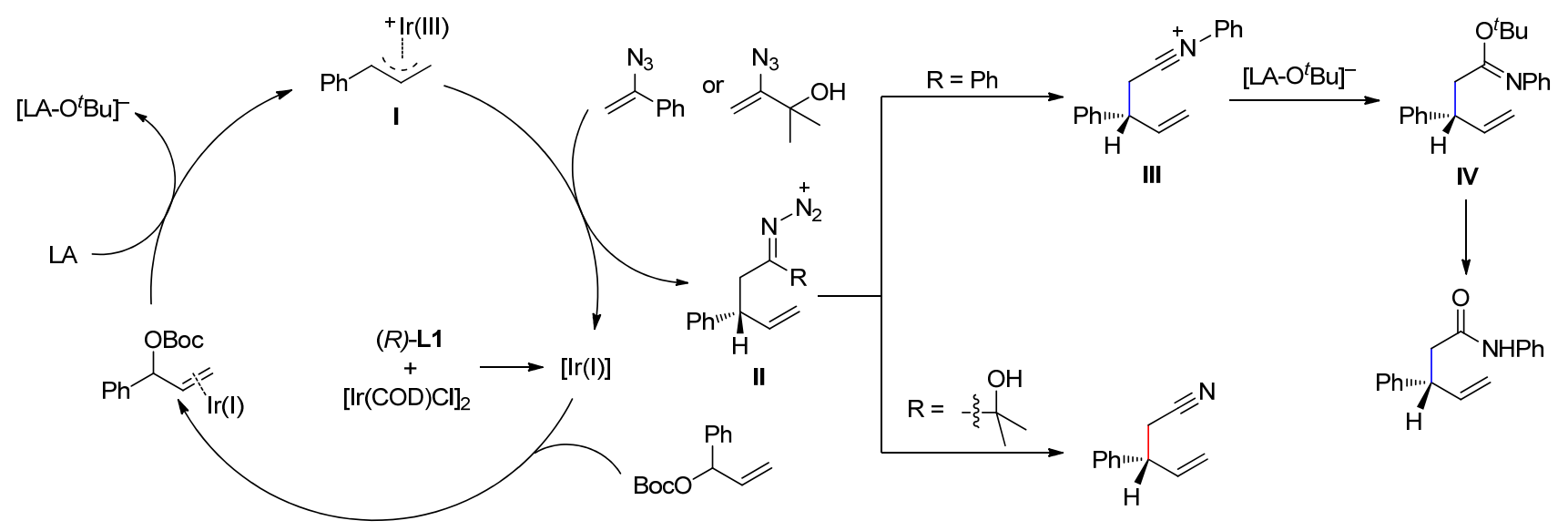

图式 3 可能的反应机理

Scheme 3 Proposed mechanism

\section{References}

[1] Cheng, Q.; Tu, H.-F.; Zheng, C.; Qu, J.-P.; Helmchen, G.; You, S.-L. Chem. Rev. 2019, 119, 1855.

[2] Takeuchi, R.; Kashio, M. Angew. Chem., Int. Ed. 1997, 36, 263.

[3] Janssen, J. P.; Helmchen, G. Tetrahedron Lett. 1997, 38, 8025.

[4] Fleming, F. F.; Wang, Q. Chem. Rev. 2003, 103, 2035.

[5] (a) Zhang, K.; Peng, Q.; Hou, X. L.; Wu, Y. D. Angew. Chem., Int. Ed. 2008, 47, 1741

(b) Trost, B. M.; Michaelis, D. J.; Charpentier, J.; Xu, J. Angew. Chem., Int. Ed. 2012, 51, 204.

[6] Han, M.; Yang, M.; Wu, R.; Li, Y.; Jia T.; Gao Y. J.; Ni H.-L.; Hu P.; Wang B.-Q.; Cao, P. J. Am. Chem. Soc. 2020, 142, 13398.

[7] Marcin, L. R.; Warrier, J.; Thangathirupathy, S.; Shi, J.; Karageorge, G. N.; Pearce, B. C.; Ng, A.; Park, H.; Kempson, J.; Li, J.;
Zhang, H.; Mathur, A.; Reddy, A. B.; Nagaraju, G.; Tonukunuru, G.; Gupta, G. V. R. K. M.; Kamble, M.; Mannoori, R.; Cheruku, S.; Jogi, S.; Gulia, J.; Bastia, T.; Sanmathi, C.; Aher, J.; Kallem, R.; Srikumar, B. N.; Vijaya, K. K.; Naidu, P. S.; Paschapur, M.; Kalidindi, N.; Vikramadithyan, R.; Ramarao, M.; Denton, R.; Molski, T.; Shields, E.; Subramanian, M.; Zhuo, X.; Nophsker, M.; Simmermacher, J.; Sinz, M.; Albright, C.; Bristow, L. J.; Islam, I.; Bronson, J. J.; Olson, R. E.; King, D.; Thompson, L. A.; Macor, J. E. ACS Med. Chem. Lett. 2018, 9, 472.

[8] Kempson, J.; Zhang, H.; Wong, M. K. Y.; Li, J.; Li, P.; Wu, D.-R.; Rampulla, R.; Galella, M. A.; Dabros, M.; Traeger, S. C.; Muthalagu, V.; Gupta, A.; Arunachalam, P. N.; Mathur, A. Org. Process Res. Dev. 2018, 22, 846.

[9] Rössler, S. L.; Petrone, D. A.; Carreira, E. M. Acc. Chem. Res. 2019, 52, 2657. 